\title{
Application of habitat modelling in river rehabilitation and artificial habitat design
}

\author{
Knut Alfredsen ${ }^{(1)}$, Peter Borsanyi ${ }^{(1)}$, Atle Harby ${ }^{(2)}$, \\ Hans-Petter Fjeldstad ${ }^{(2)}$, Sten-Enok Wersland ${ }^{(1)}$
}

Corresponding author: Knut Alfredsen, knut.alfredsen@ntnu.no

\begin{abstract}
Over the last years there has been a growing interest in river rehabilitation and the design of artificial habitat funded by an increasing knowledge of the importance of physical habitat for populations of Atlantic salmon and trout. With the current developments in two- and three-dimensional computational hydraulics, a capability of predictive hydraulic modelling has been established and modelling and analysis of the artificial habitats are thereby possible as a part of the planning stage. This have been utilised in a project to integrate hydraulic modelling tools, habitat modelling tools, river editing tools and visualization tools into a system for analysis and design of river rehabilitation projects and artificial habitat construction. Current work includes development a river editing system where the user can edit the bathymetry of the river manually or automatically by inserting standardised habitat features like current deflectors or weirs, and a strengthening of the hydraulic and habitat models to include effects of winter temperatures and ice in the analysis. Early versions and prototypes of the system have been used in the design of artificial habitat for juvenile fish and in construction of migratory habitat for adult Atlantic salmon through weir basins.
\end{abstract}

Key words. - hydraulic modelling, river restoration, habitat modelling, Atlantic salmon, environmental impact mitigation

\section{BACKGROUND}

Hydropower has been developed widely in Norwegian rivers and measures to reduce impacts on the aquatic ecosystem are an important consideration in new projects and in the process of license renewal in older projects. Over the years several measures have been used such as minimum flows, weirs, fish passages, fish stocking and artificial habitat construction. Existing artificial habitat measures include special weirs, current deflectors and substrate and cover improvement. The habitat improvements are typically used to alleviate effects of a changed flow regime in rivers with reduced flow, but they

(1) Department of Hydraulic and Environmental Engineering, Norwegian University of Science and Technology, 7491 Trondheim, Norway.

(2) SINTEF Energy Research, 7465 Trondheim, Norway 
are also applicable to other rehabilitation work in regulated rivers and in rivers affected by other means of anthropogenic encroachments (Brittain, 2003). New recommendations put an emphasis on the importance of habitat and the need to provide available habitat in rivers affected by hydropower regulations or other man-made encroachments (NOU, 1999).

With a foundation in the IFIM and PHABSIM methodology (Bovee, 1982) the River Modelling System (RIMOS) was developed in Norway twenty years ago (Vaskinn 1995). The main objective of the development work was to provide a quantitative tool for analyzing effects from flow changes on available fish habitat in hydropower development projects and to make a tool for deciding on a minimum flow regime. Further developments have been made in the River System Simulator project (Heggenes and Harby, 1995) and work have been undertaken to include linkages to two- and three-D hydraulic models and to provide a wider variety of tools for habitat analysis (Alfredsen, 1999). All of these developments lead to the current habitat analysis program (HABITAT). The scope of application has also been increased from the original minimum flow objective to include several other types of analysis linked to the interaction between available habitat and changes in instream conditions.

Using HABITAT in combination with two and three-dimensional hydraulic models we have a tool for predictive modelling of artificial habitats.
It is possible to try out different designs both with a hydraulic perspective and a biological perspective before they are built and thereby save trial and error efforts on the building site. It is also possible to include other evaluations into the design process such as winter performance and erosion and stability of the constructions. Through visualization of the results from the design process the layout of the artificial habitat can be presented to various interest groups in an efficient way and thereby work as a foundation for discussion and further refinement.

Based on data from measurements and computer simulations habitat improvements have been designed and built with different objectives. Juvenile rearing areas have been made to provide suitable shelter and rearing areas in rivers with reduced flow or altered morphological features due to flood and erosion protection. Work is under way to apply the methods to restore side channel habitat that is degraded due to lack of regular floods in regulated rivers. The method have been applied to planning and design on artificial spawning sites for salmon in a river where erosion protection works have lead to a stabilized and coarse substrate. The methods are also applied to the development of migration habitat for adult salmon through existing weir basins in regulated rivers.

Long term biological analysis of the constructed habitat have been a part of some artificial habitat projects (Arnekleiv, 1996), but this is an area 
that needs to be addressed in the future both to test if the constructed habitat areas work as planned, and to see the long term effects of the habitat improvement.

\section{HABITAT CONSTRUCTION PROCEDURE}

The process of the artificial habitat design procedure is shown in figure 1 . The procedure has the following main steps:

The first step is data collection for the site where the artificial habitat is to be built. The current procedure involves data from digital maps in combination with field measurements of bathymetry of the existing river reach. The data collection procedure follows the standard strategic random sampling procedure using a total station or a GPS based system. In cases where there is no existing river channel such as in rehabilitation projects where previous filled reaches are reconstructed, it may be necessary to extract the geometry for the hydraulic model from the digital terrain model without any field measurements. Another important part of the data preparation is the selection of discharges for the simulation. Typically several discharges will be used to analyse various features of the habitat and they can be derived from statistical analysis of flow records, from hydrological modelling of the catchment, from production simulations in case of hydropower regulations or from a combination of these sources.

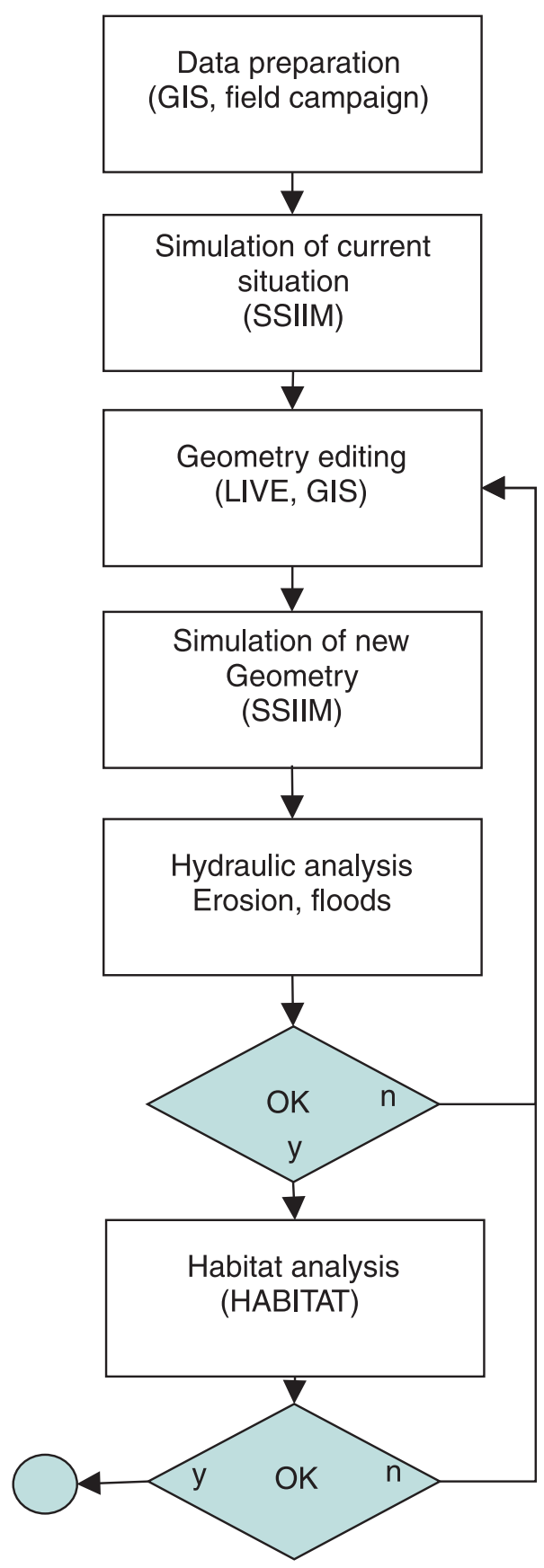

Fig. 1. - Habitat design procedure. 

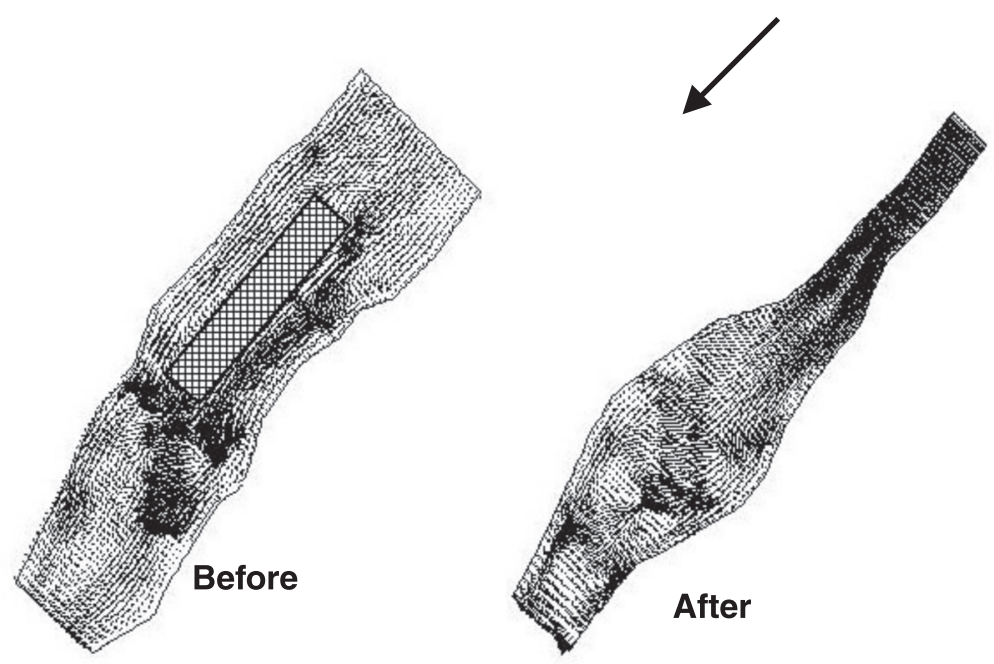

Fig. 2. - Hydraulic simulation of the Nesheim reach (From Harby, 2001). Hatched area represents an island. The length of the reach is 150 meters.

The second step involves setup and calibration of the hydraulic model for the existing reach. In the case where there is no existing river channel this step is omitted. Two existing hydraulic models have so far been used in this procedure, SSIIM (Olsen, 2000) and River2D (Steffler, 2000). Other tools may easily be adapted if they are needed. The simulation results at this stage serves as a reference for comparing changes after the editing, and they are used a foundation for deciding on what kind of artificial habitat constructs that should be used in each case.

When the foundation is defined and the type of artificial habitat is decided, the geometry is edited according to the planned artificial habitat. An interactive geometry editor (LIVE) is used in this process (Wersland, 2002). Through this the user can edit the river manually or automatically by inserting standardised habitat features into the geometry. The editor will support automatic insertion of weirs, current deflectors, substrate improvements, rock piles and pools. The editor uses inputs in the form of data from the hydraulic models or geometry data in free format, and it can export data in free format or a format readable by the simulation model. Data can also be exported to Microsoft Excel and Golden Software's Surfer program for further analysis and presentation. At the time of writing the editor is in its prototype stage.

The next step involves the simulation of the new geometry for the selected discharges using the hydraulic model. Since there will be no data for depths and velocities available for verification or calibration, the evalua- 
tion of the simulation results must be based on the experience and judgement of the operator of the program.

Based on the data from the simulation an analysis of hydraulic features is carried out and how these may impact the intended functionality of the habitat structures. This may included flood stability and how the structures operate during flood conditions, winter and ice formation processes in the reach and how this affect the functionality of the artificial habitat. Another issue that is included in this step is erosion problems and sediment deposits in the artificial habitats and on the constructions themselves. In building artificial habitats in the river channel not only the function of the habitat for its biological purpose is important, but also the long term stability of the construction and the ability of the construction to survive extreme hydrological events. If any feature is found to be inadequate the geometry of the reach should be edited to solve the problem and the process will start over from step 3.

The last step involves the habitat analysis. This is based on combining preference curves for summer and winter conditions with the hydraulic data to construct maps of usable habitat to study the spatial habitat distribution and to combine the habitat maps with time series of discharge to analyse the temporal habitat distribution and to find the duration of periods with low habitat and to identify possible bottlenecks in available habitat. If this is found to be inadequate the pro- cess will start over from step 3 with redesign of the artificial habitat.

The procedure is carried out until the results in step five and step seven are found to be satisfactory. At all time it is also important to consider the feasibility of construction of the intended changes to the river geometry. Another key issue is the data needs in the process, mainly in the form of geometry data to describe the channel and fish data to create the preference curves needed for the habitat analysis. Concerning work in existing river reaches all cases so far has included field data collected from the river. In cases where complete reconstruction of the stream has been the objective, geometry data for the simulation have been made solely from digital terrain data using the ArcView GIS. This simplifies the procedure of collecting data, but it does provide less detailed data for the study. Finding preference curves for the study site, as is the norm in application of the Norwegian habitat model (Heggenes and Saltveit, 1990; Heggenes 1992), require extensive field work to collect data for summer and winter preferences. The ability to use non-site preferences would increase the flexibility of the method and make it applicable to studies where field work is difficult or impossible. In literature there is a debate on the issue of local vs. general or regional preferences, their creation and application (Lamouroux, 1999). Many studies indicate that the winter period may be important for survival and modelling and analysis of winter habi- 
tat should if possible be included in the habitat analysis in step 6. Winter period is also important considering ice load and forces from ice break-up on the stability of the habitat constructions.

An important part of the procedure is the ability to visualise the data for the different interest groups of the project. Currently a combination of maps, graphs and animations are used to show the flow patterns and habitat availability of the constructed reach. Work is under way to be able to connect the results to photographs to provide a method of describing the interaction of the constructed habitat with the landscape and areas adjacent to the river.

\section{EXAMPLES}

The Dalåa river is a tributary to the Stjørdal river north of Trondheim and it is heavily influenced by the river regulations carried out as a part of the refurbishment of the Meråker power plant. Mean annual flow before regulation was $5.5 \mathrm{~m}^{3} / \mathrm{s}$. Dalåa is upstream of the natural areas for Atlantic salmon in Stjørdal, but it is used as rearing habitat for juvenile Atlantic salmon that is artificially planted in the river. To mitigate the low minimum discharge artificial habitats have been built at Øyvollen and Nesheim to provide suitable habitat for juvenile Atlantic salmon (Arnekleiv and Harby, 1994, Harby, 2001). So far the work has been carried out at the two study sites, but the plan is to use the results from this project to develop several more areas with habitat improvements.

The Nesheim reach has a proposed minimum flow regime of $1.3-$ $2.0 \mathrm{~m}^{3} / \mathrm{s}$. With this flow, the areas consist mostly of shallow, broken water with large boulders. The model of the river before habitat construction is show in Figure 2. An artificial habitat was made in the river with the goal to increase the useable areas by creating more pool habitat and more suitable velocity areas in the reach. The inlet to the reach was constricted, and a submerged weir was made in the lower end of the reach. In addition a current deflector was built at the downstream end, and suitable substrate was placed at several locations along the reach. The computer simulation of the original and modified reach is shown in Figure 2.

Figure 3 shows a comparison between combined depth and velocity habitat for the reach before and after the construction of the habitat improvements.

The Mandal river in southern Norway is regulated through several power plants. Downstream of the Laudal power plant intake a succession of weirs is built to maintain a water level and to provide habitat for fish in the reach. Experiences show that the migration of adult Atlantic salmon is slowed down through the weir basins most likely due to the lack of current in the weir basin. To alleviate this situation a plan was made to cut through the centre of each weir and to make a channel in each basin with 

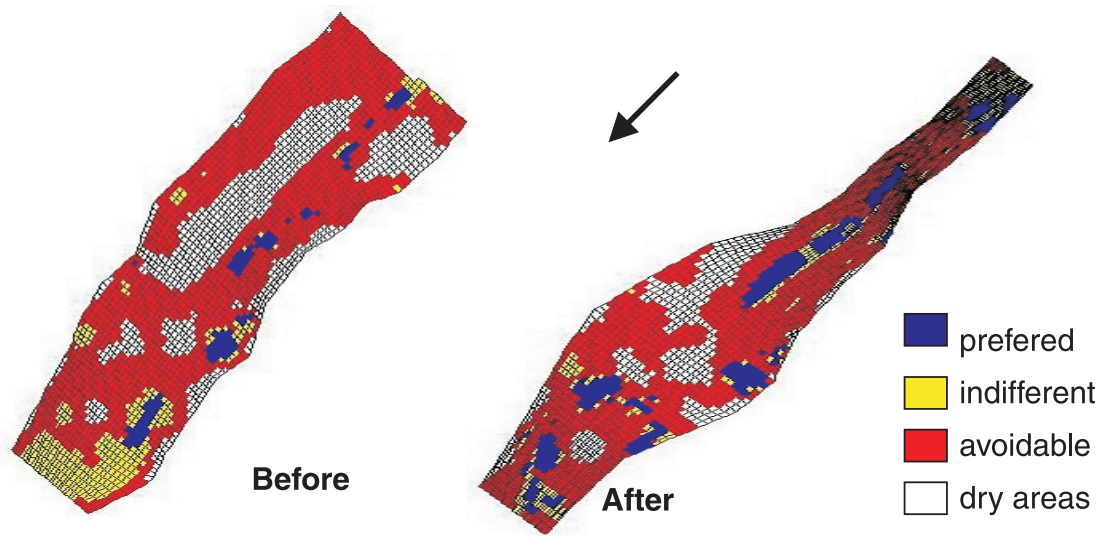

Fig. 3. - Habitat simulations for $1.3 \mathrm{~m}^{3} / \mathrm{s}$ for the original and modified reach (From Harby, 2001).

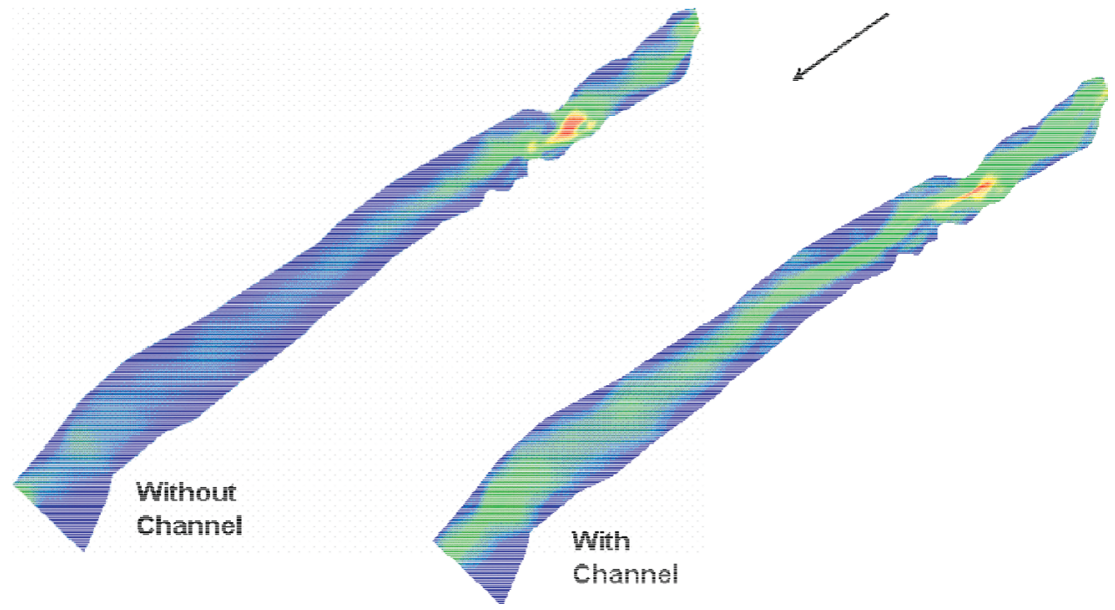

Fig. 4. - Velocity distribution in one Mandal weir basin with and without artificial channel. Velocity scale goes from red (high) to blue (low) (From Fjeldstad, 2001). Length of reach is 700 meters.

higher velocity to aid the migration of salmon through the reach. To find the effect of this the weir basin geometry was measured using a total station, and a SSIIM grid was fitted to the existing reach. The geometry was then modified with a channel following the centre of the reach, and the upstream weir was opened. The simulation of the flow in the weir basin with and without the channel and upstream opening is shown in Figure 4.

The Aurland river in western Norway was regulated for hydropower during the seventies. Lowered spring flood levels have lead to less scouring of side channels in the main river and a degradation of habitat for juvenile 


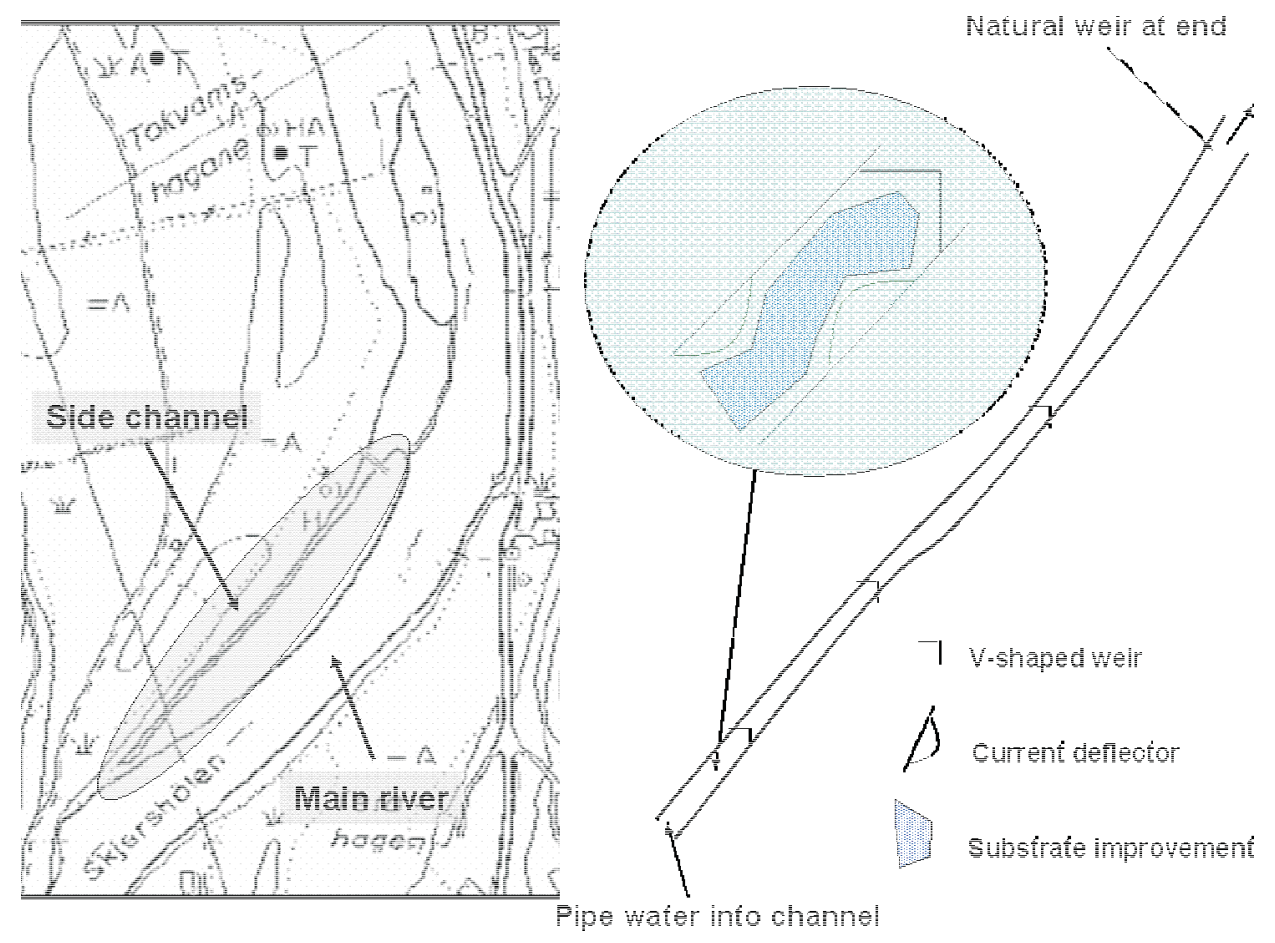

Fig. 5. - Sketch of proposed improvements in Aurland side channel.

salmon and sea-trout due to siltation and growth of vegetation. To improve the fish production potential the landowners wishes to restore the side channels and work is currently underway to design a water intake to one of the side channels and to restore instream habitat in this channel to utilize the available water. Plans include a submerged intake in the main river using a pipe to secure a stable water flow, and a succession of pools and riffles built within the channel to create habitat for juvenile fish (Figure 5). The only available data from before the regulation are photos of the channels at different discharges, so there is very little existing data for compari- son with the new designs. The photographs will be used as far as possible to restore the channel to its original habitat. Special care will be taken to avoid complete freezing of the habitat during the winter and to protect the bank side vegetation during the construction work.

\section{FURTHER WORK}

The current standard of work in Norway is to develop fish preferences for each new river that is to be analysed. After several years of application of the method there exists a 


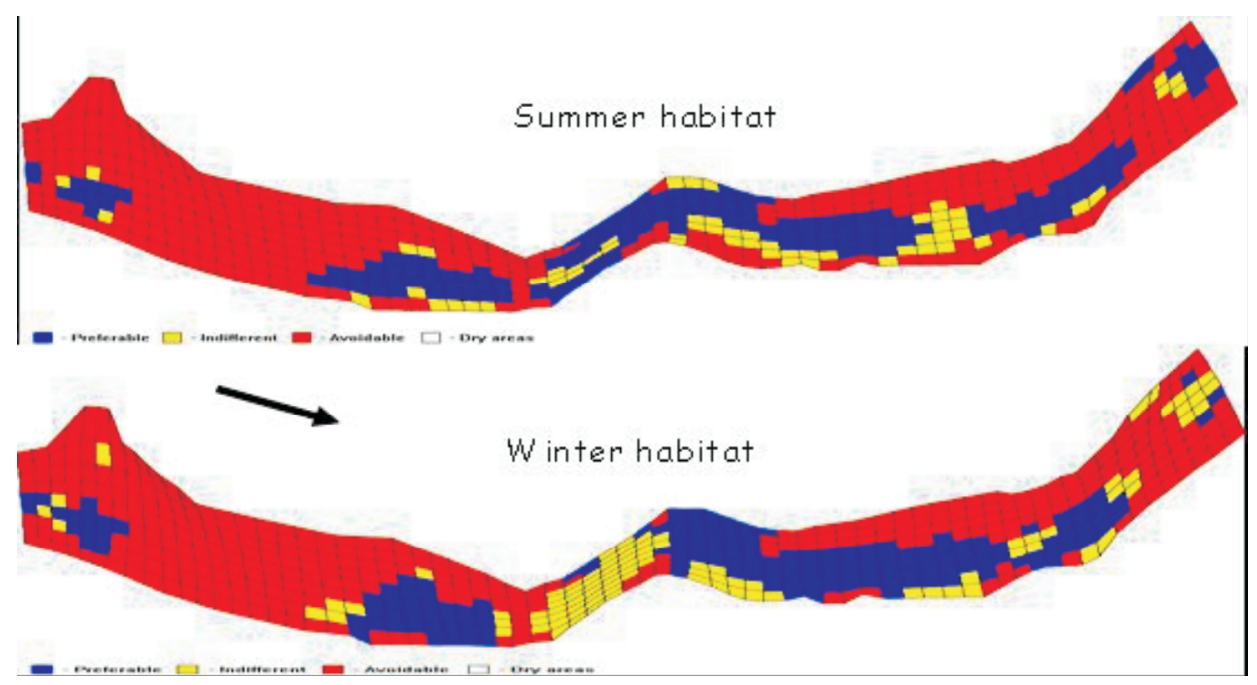

Fig. 6. - Summer and winter habitat at Øyvollen. Length of study area is 120 meters.

library of preferences for rivers in different regions and with different hydraulic characteristics (Harby et al., 1999). The question when modelling habitat in new river systems with preferences developed for other areas has not been resolved, but having a method to do this would increase the applicability of the rehabilitation method. This would particularly be the case in rivers where it is not possible to find enough fish data to create the preference curves for the specific river. This is the case in the rehabilitation of degraded channels, complete reconstruction of river reaches or the creation of rearing habitats for Atlantic salmon outside their natural areas. A possible option would be to move towards regional curves

Two topics are important concerning ice in relation to artificial habitat creation. The first topic is concerned with winter habitat and the performance of the various artificial habitats during winter conditions. The second topic is the stability of the artificial stream during winter and particularly during ice break-up. The effect of ice on winter habitat has been discussed in literature, and some research have been carried out to investigate fish behaviour in winter and various ice effects on the habitat (e.g. Heggenes et al. 1993, Cunjak et al. 1999). Work is underway to further develop the habitat modelling tools to include various forms of winter habitat analysis as a part of the procedure (Alfredsen and Tesaker, 2002). The methods used so far is comparing winter and summer habitats (Figure 6) and including ice analysis based on free surface hydraulics in the model. It was observed during freeze up at Øyvollen in autumn 2002 


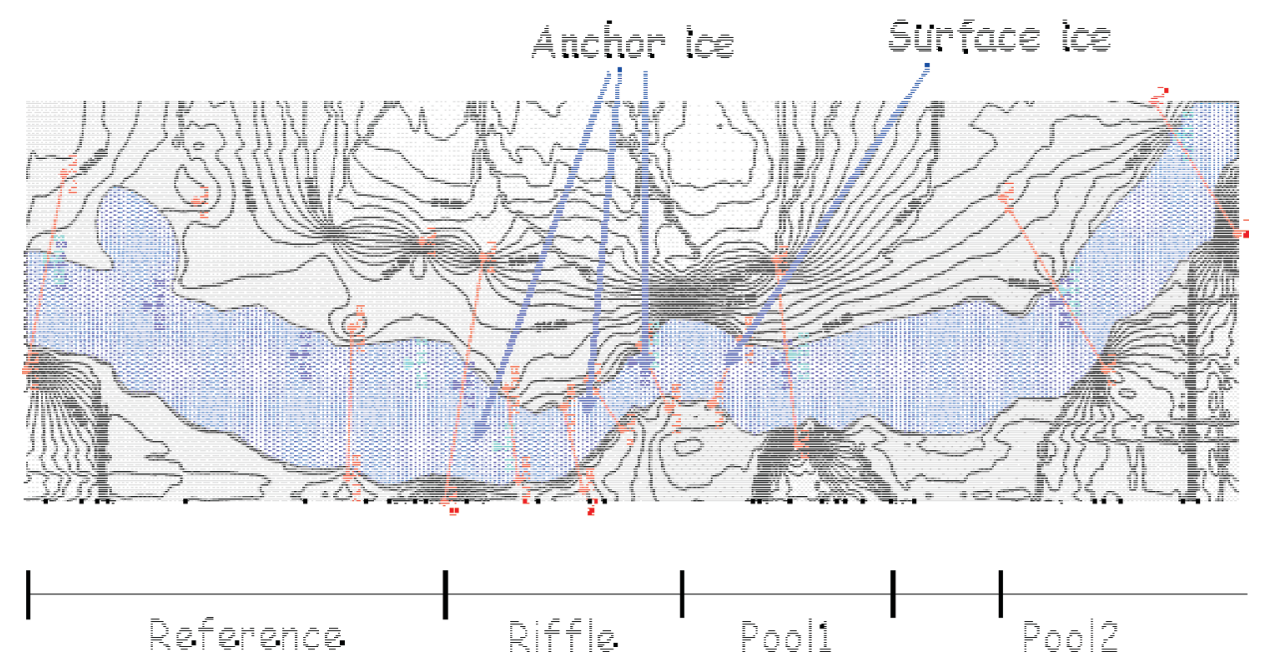

Fig. 7. - Ice formation at Øyvollen.

that the entire habitat was flooded due to formation of three anchor ice dams in the riffles and a surface cover over the pool areas. At time of freezeup water covered the entire reach also the areas normally restricted by current deflectors in the habitat area (Figure 7).

Erosion and sedimentation can alter the habitats after they have been built. This can both influence the biological performance of the habitats and the stability of the structures themselves. During the fish monitoring programme at the Øyvollen reach in Dalåa Arnekleiv (1996) found that fine sediments accumulated in one of the pool habitats and filled in the artificial substrate that was made in that area. Pegg (2003) simulated deposition of sediments in the reach using the SSIIM model to study the performance of the various habitats during high water conditions. Preliminary results from this simulation shows that

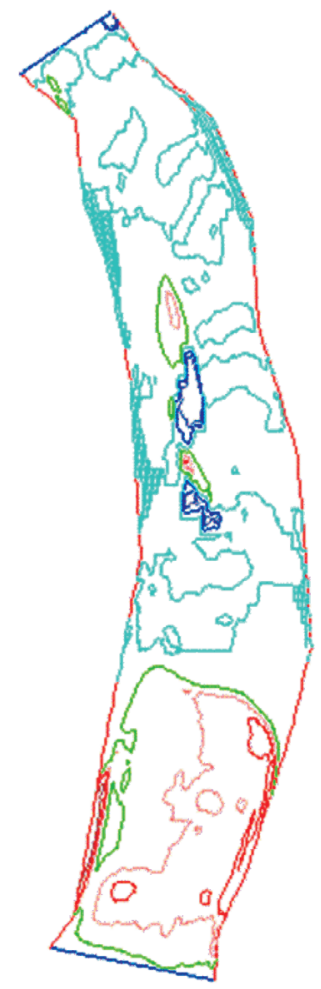

Fig. 8. - Simulation of sediment deposit at Øyvollen during flood conditions. 
the pool receive deposits of fine sediments $\left(2 \times 10^{-3} \mathrm{~m}\right)$ under flood conditions (Figure 8). More data is needed to further analyse if this is due to sediments transported into the reach from upstream sites or if the sediments are caused by internal erosion in the reach.

Testing the validity of the methods has so far been a process with two objectives. The first is to test the hydraulic models used and to try to verify their performance as tools for predicting hydraulic variables in unmeasured geometries. Most of this work has so far been concerned with the accuracy of the model in laboratory and field experiments (Kohler, 2001; Booker, 2003), and less with verification of the predicted artificial habitat. A further area of study is to find the range of cases where the method is applicable, and to identify river types where the method may not be usable. The experiences so far with rivers ranging from small stream with $.2 \mathrm{~m}^{3} / \mathrm{s}$ discharge to larger rivers with over $100 \mathrm{~m}^{3} / \mathrm{s}$ shows that the hydraulic models are applicable to all study rivers. Steep rivers with large bed roughness will require geometry data on a very detailed scale that may make the application not feasible due to the fieldwork required. The second objective is to monitor how the artificial habitats are utilised by the fish. A monitoring programme was designed and carried out after the developments at Øyvollen reach of the Dalåa river (Arnekleiv, 1996). One-year old marked juvenile Atlantic salmon was stocked both in the improved sections and in an upstream reference section to a high density. Densities of fish were then determined by electro fishing several times after the release. Results in the spring after the release showed higher densities within the artificial habitat reach than in the reference section. This may be due to either higher survival rate in the artificial habitat area or fish moving from the reference section to the improved areas. Further studies of this kind should be undertaken in more areas with artificial habitat to provide more data on how fish uses the habitat and what kind of combination works best. Another important issue is effects on sediments and ice on survival and habitat use. The above mentioned experiment in Dalaå showed that one area in the artificial reach gave a lower density than expected and this was the part of the habitat that had most sediment deposits (Arnekleiv, 1996).

The approach with simulations of river rehabilitation is interesting due to its ability to predict the effect of the changes without to need to do any large scale field trials. This can be used to improve the design process and the planning of the construction work. It also gives a visual explanation of the habitat improvement structures that can be used to present the work to various interest groups in the river and it will work as a mean to enhance the discussion around the planned improvement works. 


\section{CONCLUSION}

We have found computer simulations an efficient tool in the design and development of artificial habitats. The method is useful both in the design process and as a tool for presenting possible solutions and their effects to the different interest groups in the river basins. With an increased interest in habitat improvement the methods will probably see more use in the future, and this will further improve the results through more experience and more data. Important areas for future research and development is in application of habitat preferences, testing and verification of hydraulic and biological methods, erosion and sedimentation in man made habitats and in winter performance of the habitats. Work is under way in several of these areas, and we hope to have further developments available in the near future.

\section{REFERENCES}

Alfredsen (1999). An object-oriented framework for application development and integration in hydroinformatics. Doctoral thesis. Department of hydraulic and environmental engineering, NTNU.

Alfredsen and Tesaker (2002). Winter habitat assessment strategies and incorporation of winter habitat in the Norwegian habitat assessment tools." Hydrological Processes 16(4) pp. 927 $-936$.

Arnekleiv, J. V. and A. Harby (1994). Biotope Improvement Analysis in the River Dalåa with the River System
Simulator. 1st International Symposium on Habitat Hydraulics, Trondheim, Norway, NTH.

Arnekleiv, J. V. (1996). Effekt av habitatjusteringer på fisk i Dalåa. (Effects of habitat improvements on fish population in Dalåa [In Norwegian]). Fiskesymposiet 1996 Foredragssamling, pp $152-162$, EnFO publikasjon 128-1996.

Booker (2003). Hydraulic modelling of fish habitat in urban rivers during high flows. Hydrological Processes 17: 577 -599 .

Bovee, K. D. (1982). A guide to stream habitat analysis using the instream flow incremental methodology. Fort Collins, Colorado, National Biological Service

Brittain, J. (2003). Weirs as a Mitigation Measure in Regulated Rivers - The Norwegian Experience. Canadian Water Resources Journal, vol 28, no 2, pp $217-229$.

Cunjak, R., T. D. Prowse and D. L. Parrish (1998). "Atlantic salmon (Salmo salar) in winter: "the season of parr discontent"?" Canadian Journal of Fisheries and Aquatic Sciences 55: 161-180.

Fjeldstad, H.-P. (2001). Numerical modelling tools for predicting physical habitat adjustments. In: T. Taugbøl and J.H L'Abèe-Lund (eds) Physical habitat restoration in canalized watercourses - possibilities and constraints. NVE Report 7-2001.

Harby, A. (2001). Simulering av habitatforbedrende tiltak i Dalåa ved Nesheim. [Simulation of habitat-improvements at Nesheim in Dalåa (In Norwegian)] SINEF Energy Research technical report TR A5485.

Harby, A., et.al. (1999). Ecohydraulics 1999. Salt Lake City, Utah.

Heggenes, J., O. M. W. Krog, O. R. Lindås, J. G. Dokk and T. Bremnes (1993). "Homeostatic behaviour responses in a changing environment: brown trout (Salmo trutta) becomes 
nocturnal during winter." Journal of Animal Ecology 62: 295-308.

Heggenes, J. and Saltveit, S.J. (1990). Seasonal and spatial microhabitat selection in young Atlantic salmon (Salmo salar) and brown trout (Salmo trutta) in a Norwegain river. Trans. Am. Fish. Society 119, pp 101-111.

Heggenes, J. (1992). Fysisk miljø for fisk i rennende vann (Physical environment for fish in rivers [In Norwegian]). In: Vassdragssimulator. Økologiske data for fisk og bunndyr. LFI Rapport nr. 132, del I, pp 3-36.

Heggenes and Harby (1995). HABITAT Users Manual. In: $\AA$. Killingtveit, K. Alfredsen and T.H. Bakken (eds). The River System Simulator - Users manual and program guide. Norwegian Hydrotechnical Laboratory Report.

Kohler, B. (2001). Hydraulic Parameters controlling fish behaviour and stranding in a laboratory river. Diploma thesis, University of Stuttgart, Institute of hydraulic engineering.

Lamouroux, N. H. Capra, M. Pouilly and Y. Souchon (1999). Fish habitat preferences in large streams of southern France. Freshwater Biology, vol 42, pp $673-678$.

NOU (1999). Til laks åt alle kan ingen gjera? [Report from the Wild Salmon Committe, (In Norwegian with English summary)]. Norges Offentlige Utredninger 1999: 9.

Olsen, N.R.B. (2000). A three-dimensional numerical model of sediment movements in water intakes with multiblock option. Version 1.1 and 2.0 for OS/2 and Windows. User's Manual. Department of hydraulic and environmental engineering, NTNU, Trondheim, Norway

Pegg, I. (2003). Geomorfologiske endringer rundt habitatforbedrende tiltak. (Geomorphological changes in habitat improvements [In Norwegian]). Project report, Dept. of hydraulic and environmental engineering, NTNU, 9 pages.

Steffler, P. (2000). River 2D. Two dimensional depth averaged model of river hydrodynamics and fish habitat. Users Manual. University of Alberta.

Vaskinn (1985). Fysisk Beskrivende Vassdragsmodell [The River Modelling System RIMOS, (In Norwegian)]. SINTEF NHL Report A1.

Wersland S. E. (2002). Reabilitering og restaurering av vassdrag: Kravspesifikasjon for en interaktiv vassdragseditor. [Rehabilitation and restoration of river reaches: requirements specification for a interactive geometry editor. (In Norwegian)]. Project report. Department of hydraulic and environmental engineering, NTNU. 
